FRUET, A.P.B. et al. Legislação e implementação dos programas de controle de qualidade em frigoríficos sob fiscalização federal no Brasil. PUBVET, Londrina, V. 8, N. 13, Ed. 262, Art. 1740, Julho, 2014.

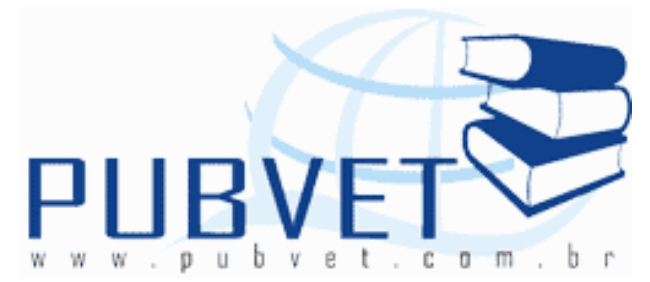

PUBVET, Publicações em Medicina Veterinária e Zootecnia.

\title{
Legislação e implementação dos programas de controle de qualidade em frigoríficos sob fiscalização federal no Brasil
}

\footnotetext{
Ana Paula Burin Fruet*1, Flávia Santi Stefanello ${ }^{1}$, Jackeline Karsten Kirinus ${ }^{2}$, Luis Fernando de Pelegrini ${ }^{3}$, José Laerte Nörnberg ${ }^{4}$, Andréa Cristina Dörr ${ }^{5}$
}

${ }^{1}$ Médicas Veterinárias, Alunas do Programa de Pós-Graduação em Ciência e Tecnologia de Alimentos da Universidade Federal de Santa Maria (UFSM). *Autor para correspondência: ap_burin@hotmail.com

${ }^{2}$ Médico Veterinária, Professora do curso de Medicina Veterinária, Universidade do Oeste de Santa Catarina (UNOESC).

${ }^{3}$ Médico Veterinário, Professor Adjunto do Departamento de Medicina Veterinária Preventiva (UFSM).

${ }^{4}$ Médico Veterinário, Professor Associado do Departamento de Tecnologia e Ciência dos Alimentos (UFSM).

${ }^{5}$ Economista, Professora Adjunto do Departamento de Ciências Econômicas (UFSM).

\section{Resumo}

Em decorrência da necessidade de produzir alimentos com qualidade e seguros, a partir da década de 90 , surgiram os programas de controle de qualidade no Brasil. Esses são constituídos por quatro planos principais: Procedimentos Operacionais Padronizados (POP), Boas Práticas de Fabricação 
FRUET, A.P.B. et al. Legislação e implementação dos programas de controle de qualidade em frigoríficos sob fiscalização federal no Brasil. PUBVET, Londrina, V. 8, N. 13, Ed. 262, Art. 1740, Julho, 2014.

(BPF), Procedimento Padrão de Higiene Operacional (PPHO) e Análise de Perigos e Pontos Críticos de Controle (APPCC). Esta revisão bibliográfica tem o objetivo de verificar se a legislação brasileira que rege os programas de controle de qualidade em frigoríficos sob fiscalização federal garante a produção de alimentos seguros. O estudo revela que ocorreu mudanças expressivas na legislação brasileira quanto ao controle de qualidade na produção de alimentos, as quais podem ser evidenciadas na Circular $n^{\circ} .175$ de 2005 do Ministério da Agricultura, Pecuária e Abastecimento (MAPA), que uniu os principais programas em um único documento e criou os programas de autocontrole, além de passar a responsabilidade de produzir alimentos seguros (que antes era da fiscalização federal), para a indústria. Ainda, identificou-se que a legislação brasileira e a literatura correspondente apresentam dados suficientes sobre implementação de programas de qualidade, além da existência de um padrão a ser seguido pelas empresas ao aderir os programas de autocontrole. Sendo assim, empresas produtoras de alimentos que seguem a legislação federal e realizam implementação adequada de programas de controle da qualidade ofertam produtos seguros e viabilizam a comercialização com outros países.

Palavras-chave: garantia da qualidade; carne; segurança alimentar.

\title{
Legislation and implementation of quality control programs in slaughterhouses under federal oversight in Brazil
}

\begin{abstract}
Due to the need to produce quality and safe food, the quality control programs emerged in Brazil since the 90s. These programs are formed by four major plans: Standard Operating Procedures (SOP), Good Manufacturing Practices (GMP), Sanitation Standard Operating Procedures (SSOP) and Hazard Analysis and Critical Control Points (HACCP). This literature review aims to determine whether the Brazilian legislation which rules quality control programs in
\end{abstract}


FRUET, A.P.B. et al. Legislação e implementação dos programas de controle de qualidade em frigoríficos sob fiscalização federal no Brasil. PUBVET, Londrina, V. 8, N. 13, Ed. 262, Art. 1740, Julho, 2014.

slaughterhouse under federal inspection ensures the production of safe food. The study reveals significant changes in Brazilian law regarding the quality control in food production. Such changes can be evidenced in Circular 175/2005 Ministry of Agriculture (MAPA), which brought together the main programs in a single document and created the programs of self-control, in addition to shifting a formerly federal inspection responsibility of producing safe food on to industry. It was also identified that the Brazilian legislation and the corresponding literature have sufficient data on the implementation of quality programs, being evident that there was a pattern to be followed by companies to join the program of self-control. On this basis, food companies that follow federal legislation and conduct proper implementation of quality control programs ensure the production of safe food and enable marketing with other countries.

Keywords: quality insurance; meat; food safety.

\section{INTRODUÇÃO}

Segundo a FAO (2012), o Brasil é o segundo maior produtor de carne bovina do mundo, depois dos Estados Unidos, e terceiro maior produtor de carne de frango, sendo Estados Unidos e a China detentores das primeiras colocações no ranking. No entanto, o Brasil é reconhecido por ser o maior exportador mundial dos produtos supracitados. Por esse motivo, a cadeia de produção cárnea apresenta posição de destaque na economia brasileira, ocupa grande área do território nacional, contribui para a geração de empregos e renda de milhões de brasileiros.

Concomitantemente ao crescimento do mercado cárneo brasileiro, elevam-se as exigências do consumidor e, neste contexto, diversos conceitos e práticas, como programas de qualidade, ganham evidência no setor produtivo de carne. Além disso, esta produção deve respeitar o bem estar animal, não causar danos ao meio ambiente (SEPÚLVEDA et al., 2011) e principalmente, de 
FRUET, A.P.B. et al. Legislação e implementação dos programas de controle de qualidade em frigoríficos sob fiscalização federal no Brasil. PUBVET, Londrina, V. 8, N. 13, Ed. 262, Art. 1740, Julho, 2014.

acordo com Krystallis e Arvanitoyannis (2006), que os produtos sejam seguros, saborosos e nutritivos.

Os principais programas de qualidade implementados em frigoríficos são: Procedimentos Operacionais Padronizados (POP), Boas Práticas de Fabricação (BPF), Procedimentos Padrão de Higiene Operacional (PPHO) e Análise de Perigos e Pontos Críticos de Controle (APPCC). Os três últimos citados fazem parte dos programas de autocontrole previsto na Circular $n^{\circ} .175$ de 2005, de acordo com o Ministério da Agricultura, Pecuária e Abastecimento (BRASIL, 2005a).

A implementação desses programas em empresas de alimentos fortalece e contribui para competitividade com mercados mundiais. No entanto, frigoríficos de pequeno e médio porte apresentam dificuldade para implementar a gestão da segurança alimentar (FIELDING et al., 2011). A falta de conhecimento, motivação e confiança na legislação sobre segurança alimentar aliado à falta de recursos financeiros e as limitações de recursos humanos, são as principais barreiras para o cumprimento dos requisitos exigidos pelo controle oficial (KARIPIDIS et al., 2009; JIANU; CHIS, 2012).

Objetiva-se com este trabalho verificar se a legislação brasileira que rege os programas de controle de qualidade em frigoríficos sob fiscalização federal garante a produção de alimentos seguros.

\section{LEGISLAÇÃO QUE REGE OS PROGRAMAS DE AUTOCONTROLE}

O cenário de expansão do mercado cárneo está associado ao aumento das exigências dos consumidores em relação à qualidade do produto, tornando inevitável o aperfeiçoamento de toda a cadeia produtiva (MOMBACH et al., 2010). Devido à necessidade de produzir alimentos seguros, a partir da década de 90, surgiram os programas de controle de qualidade no país. Portanto, pode-se dizer que esses programas são recentes no mercado brasileiro, principalmente, quando comparado com o regulamento que dispõe sobre a 
FRUET, A.P.B. et al. Legislação e implementação dos programas de controle de qualidade em frigoríficos sob fiscalização federal no Brasil. PUBVET, Londrina, V. 8, N. 13, Ed. 262, Art. 1740, Julho, 2014.

inspeção industrial e sanitária de produtos de origem animal (RIISPOA) que foi criado em 1950 (Figura 1).

O programa de BPF foi o primeiro a ser instituído - Portaria $n^{\circ} .1428$ de 1993 do Ministério da Saúde (MS) - e estabelece as orientações necessárias para executar as atividades de inspeção sanitária de forma a avaliar as boas práticas, com a finalidade de obter padrões de identidade e qualidade de produtos e serviços na área de alimentos (BRASIL, 1993). Já em 1997, através da Portaria n 368 do Ministério da Agricultura, Pecuária e Abastecimento (MAPA), aprovou-se o regulamento técnico sobre as condições higiênicosanitárias e de BPF para estabelecimentos elaboradores/industrializadores de alimentos, ao considerar a necessidade de padronizar os processos de elaboração dos produtos de origem animal (BRASIL, 1997a).

Em 2002, juntamente com a aprovação das verificações do programa de BPF, foi estabelecido o regulamento técnico de Procedimentos Operacionais Padronizados (POP), na Resolução - RDC no. 275 do MS. O POP é um procedimento escrito de forma objetiva, que estabelece instruções sequenciais para a realização de operações rotineiras e específicas na produção, armazenamento e transporte de alimentos (BRASIL, 2002). Essa Resolução também busca contribuir para a garantia das condições higiênico-sanitárias necessárias ao processamento e industrialização de alimentos, complementando as BPF.

Em decorrência do aumento do número de casos de doenças transmitidas por alimentos (DTAs) relacionadas com fornecedores de refeições prontas, foi elaborada a Resolução - RDC n. 216 de 2004 do MS. Tal resolução estabelece procedimentos de boas práticas para serviços de alimentação, a fim de garantir as condições higiênico-sanitárias do alimento preparado e minimizar os riscos à saúde do consumidor. Além disso, propõe uma avaliação das BPF em estabelecimentos de produção ou de comercialização de alimentos, por meio de utilização de questionários apropriados (BRASIL, 2004). 
FRUET, A.P.B. et al. Legislação e implementação dos programas de controle de qualidade em frigoríficos sob fiscalização federal no Brasil. PUBVET, Londrina, V. 8, N. 13, Ed. 262, Art. 1740, Julho, 2014.

A relevância do sistema APPCC para corroborar com a produção de alimentos seguros foi discutido internacionalmente (MIYAGUSKU et al., 2011) e, a partir da Circular no. 272 de 1997 do MAPA, instituiu-se PPHO e o Sistema de Análise de Risco e Controle de Pontos Críticos (ARCPC) em estabelecimentos brasileiros envolvidos com o comércio internacional de carnes, produtos cárneos, leite, produtos lácteos, mel e produtos apícolas (BRASIL, 1997b). No entanto, foi através da Portaria n. 46 de 1998 que ocorreu a oficialização da implementação gradativa do APPCC em indústrias de produtos de origem animal sob o regime do Serviço de Inspeção Federal (SIF), de acordo com o manual genérico de procedimentos, anexo a essa Portaria.

Em 2003, a fim de preparar os estabelecimentos exportadores para as exigências dos mercados, foi emitido as instruções para elaboração e implementação dos sistemas PPHO e APPCC nos estabelecimentos habilitados à exportação de carnes através da Circular no. 369 do MAPA (BRASIL, 2003).

A partir de 2005, houve uma mudança no posicionamento do SIF com respeito aos programas de autocontrole. A denominação programas de autocontrole surgiu na tentativa de incluir todos os controles sanitários de alimentos que garantem a inocuidade dos produtos em um documento único, a Circular $n^{\circ} .175$ de 2005. Este programa inclui PPHO, APPCC e de uma forma mais ampla o BPF (BRASIL, 2005a).

É observado no referido documento, que o SIF transmite a tarefa de monitoramento dos programas para a indústria, portanto, hoje é responsabilidade da empresa implementar e executar os programas de Autocontrole. Este fato pode ser evidenciado na Circular nº 176 de 2005, em que é relatado que esses programas fundamentam-se na responsabilidade dos estabelecimentos de garantir a qualidade higiênico-sanitária e tecnológica dos seus produtos, através de um sistema de controle de qualidade apropriado para evitar a consolidação dos perigos à saúde pública e de outros atributos de qualidade. Além disso, a empresa é responsável por gerar registros e informações sobre o monitoramento dos programas de autocontrole, de forma 
FRUET, A.P.B. et al. Legislação e implementação dos programas de controle de qualidade em frigoríficos sob fiscalização federal no Brasil. PUBVET, Londrina, V. 8, N. 13, Ed. 262, Art. 1740, Julho, 2014.

que o sistema possa ser submetido à verificação realizada pelo SIF (BRASIL, 2005b).

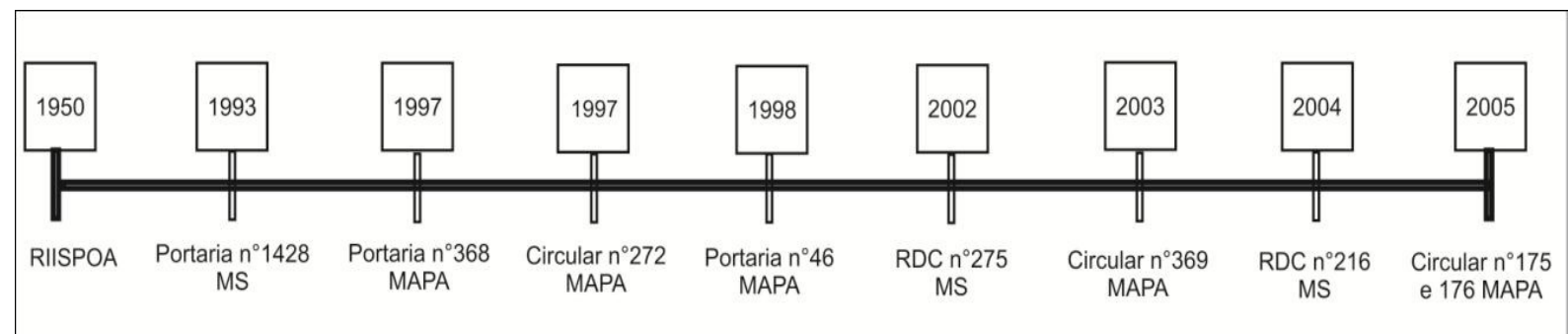

Figura 1 - Cronologia da legislação brasileira a respeito de controle de qualidade.

\section{IMPLEMENTAÇÃO DOS PROGRAMAS DE AUTOCONTROLE}

As BPF são o primeiro programa que deve ser implementado para garantir a inocuidade dos alimentos (SANTOS, 2008). Inicialmente, para implementar, deve-se fazer um levantamento das instalações da empresa. Após, deve ser elaborado o programa de acordo com a Portaria $n^{\circ} .368$ de 1997 e Circular n. 175 de 2005, de maneira que sejam incluídos 16 pontos de monitoramento, constituídos por: manutenção das instalações e equipamentos; vestiários e sanitários; iluminação; ventilação; água de abastecimento; águas residuais; controle integrado de pragas; limpeza e sanitização; higiene, hábitos de higiene e saúde dos operários; procedimentos sanitários das operações; controle de matérias-primas, ingredientes e material de embalagem; controles de temperaturas; calibração e aferição de instrumentos de controle de processos; APPCC; testes microbiológicos; certificação dos produtos exportáveis (BRASIL, 2005a).

É importante ressaltar que, apesar do plano APPCC e limpeza e sanitização (PPHO) estarem contidos nos itens citados, estes podem ser implementados separadamente, pois constituem programas independentes. Além disso, programa BPF não é limitado apenas aos pontos citados, ainda podem ser adicionados programas específicos, tais como, controle de produtos 
FRUET, A.P.B. et al. Legislação e implementação dos programas de controle de qualidade em frigoríficos sob fiscalização federal no Brasil. PUBVET, Londrina, V. 8, N. 13, Ed. 262, Art. 1740, Julho, 2014.

químicos, rastreabilidade, "recall" (MIYAGUSKU et al., 2011), programas de monitoramento de bem-estar animal, maturação sanitária, materiais específicos de risco, controle de resíduos biológicos, controle de resíduos não comestíveis e treinamento de equipe.

As informações adicionadas em cada item citado devem detalhar o procedimento, a frequência de execução da atividade, pessoas responsáveis, ações corretivas e preventivas, registros e processo de verificação (SANTOS, 2008; MIYAGUSKU et al., 2011). Entretanto, existem algumas deficiências no programa BPF, pois pode apresentar-se extremamente genérico, sem indicar riscos específicos. Por isso, outros programas são importantes para garantir a segurança alimentar (MIYAGUSKU et al., 2011).

Os POP colaboram para construir os programas de qualidade. Portanto, o POP pode ser descrito como o primeiro item do manual de BPF e deve conter informações sobre procedimentos operacionais, como: quem é o responsável por executá-lo, equipamentos necessários, descrição do procedimento, resultados esperados, monitoramento e registros. Além desses itens, é indicado que haja ações corretivas a serem tomadas quando a tarefa for elaborada incorretamente (MIYAGUSKU et al., 2011).

Além do programa de boas práticas, indústrias frigoríficas necessitam de programa de higienização, uma vez que durante o processo de fabricação de alimentos, verifica-se o acúmulo de restos de alimentos, corpos estranhos, substâncias químicas e microrganismos, estes materiais indesejáveis são designados de resíduos ou sujidade que podem comprometer a inocuidade dos produtos (ESAC, 2000). Portanto, preconiza-se que indústrias sejam higienizadas com frequência, passando por processos de limpeza e sanitização (SANTOS, 2008) que estão previstos no PPHO. Esses processos devem respeitar a seguinte sequência de operações: remoção de resíduos sólidos, pré-enxágue com água, aplicação de detergente, enxágue com água, sanitização e enxágue com água (PRATA; FUKUDA, 2001; CONTRERAS et al., 2002). Além disso, é importante salientar que o PPHO é dividido em dois 
FRUET, A.P.B. et al. Legislação e implementação dos programas de controle de qualidade em frigoríficos sob fiscalização federal no Brasil. PUBVET, Londrina, V. 8, N. 13, Ed. 262, Art. 1740, Julho, 2014.

procedimentos, segundo a Circular no. 369 (BRASIL, 2003), sendo composto pelas atividades pré-operacionais e operacionais.

O programa de PPHO deve conter a data e assinatura do indivíduo com maior autoridade no estabelecimento, nome do responsável pelos procedimentos executados em cada seção, procedimentos de limpeza e sanitização das instalações e equipamentos já citados anteriormente, procedimentos de monitoração, ações corretivas, medidas preventivas e registros (BRASIL, 2003).

O procedimento de verificação do PPHO é realizado pelo SIF de acordo com a Circular n. 176 de 2005, de maneira que quando identificado uma deficiência de execução do PPHO, que possa comprometer a integridade do produto que será ofertado ao consumo, o SIF local pode adotar as seguintes providências: interdição dos equipamentos de processo, utensílios e seções, apreensão dos produtos produzidos no turno de trabalho correspondente a verificação ou ainda a condenação do produto. Em quaisquer dessas ações, o SIF deverá comunicar à direção da empresa o resultado da verificação e as ações adotadas através do preenchimento do Registro de Não-Conformidade (RNC) (BRASIL, 2005b).

Enquanto que o plano APPCC deve ser elaborado após haver os programas pré-requisitos para assegurar a produção de alimentos seguros, estes são BPF, POP, PPHO (MIYAGUSKU et al., 2011). Segundo a Portaria nº. 46 de 1998, o APPCC está fundamentado na prevenção, eliminação ou redução dos perigos em todas as etapas da cadeia produtiva. Com essa finalidade, foram estabelecidos sete princípios básicos do sistema: identificação do perigo, identificação do ponto crítico, estabelecimento do limite crítico, monitoração, ações corretivas, procedimentos de verificação e registros de resultados (BRASIL, 1998). É importante salientar que antes de iniciar a implementação dos sete princípios (identificação do perigo, identificação do ponto crítico, estabelecimento de limite crítico, monitoração, ações corretivas, verificação, 
FRUET, A.P.B. et al. Legislação e implementação dos programas de controle de qualidade em frigoríficos sob fiscalização federal no Brasil. PUBVET, Londrina, V. 8, N. 13, Ed. 262, Art. 1740, Julho, 2014.

registros), deve-se criar uma equipe treinada, descrever o produto e construir um fluxograma da produção (FIGUEIREDO; NETO, 2001).

Neste contexto, uma equipe com boa compreensão do processo de produção deve ser formada e capacitada, além da definição de um líder para organizar as atividades e fazer registros das decisões tomadas. Ressalta-se que é necessária experiência técnica, bem como o conhecimento prático do trabalho de produção realizado, além de algumas habilidades em APPCC (STANLEY et al., 2011; KARAMAN et al., 2012).

\section{Sete princípios para implementação do APPCC}

\section{Identificação do perigo}

Refere-se a perigo, qualquer fator que possa comprometer a saúde do consumidor. Estes são classificados como perigos químicos, físicos e biológicos (RIBEIRO-FURTINI; ABREU, 2006; MATIAS, 2007). É indicado a elaboração de uma listagem de perigos durante o processo de produção (MIYAGUSKU et al., 2011) e também a avaliação quanto ao risco, severidade, existência de medidas de controle e se é um perigo significativo (CONTRERAS et al., 2002).

\section{Identificação do ponto crítico}

Segundo Ribeiro-Furtini e Abreu (2006), Ponto Crítico de Controle (PCC) é qualquer ponto, etapa ou procedimento que, ao ser aplicado medidas preventivas, mantêm um perigo identificado sob controle.

Geralmente, para identificar o PCC utiliza-se uma árvore decisória de PCC que utiliza perguntas e respostas para defini-los (Figura 2). 
FRUET, A.P.B. et al. Legislação e implementação dos programas de controle de qualidade em frigoríficos sob fiscalização federal no Brasil. PUBVET, Londrina, V. 8, N. 13, Ed. 262, Art. 1740, Julho, 2014.

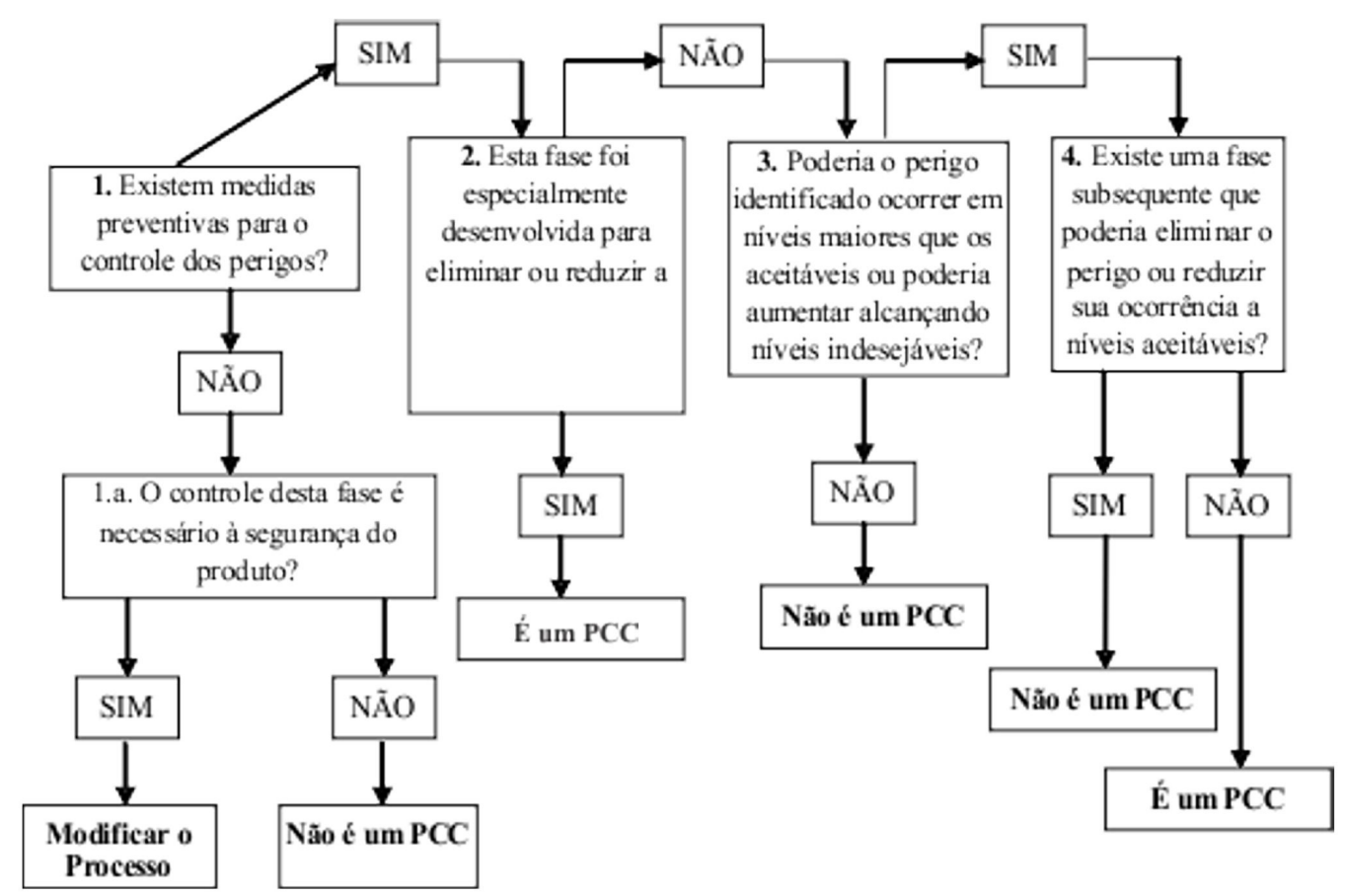

Figura 2 - Árvore decisória elaborada pelos autores para identificar o PCC.

A árvore decisória empregada nesta revisão está de acordo com a legislação (BRASIL, 2003) e literatura (CONTRERAS et al., 2002; SANTOS, 2008; MIYAGUSKU et al., 2011).

\section{Estabelecimento do limite crítico}

Os limites críticos que precisam ser cumpridos em cada um dos pontos críticos de controle devem ser listados, e deverão ser determinados de maneira que, no mínimo, assegurem que o padrão de desempenho estabelecido pela legislação ou literatura científica pertinente ao processo ou ao produto seja cumprido (BRASIL, 2003). São valores máximos e/ou mínimos que caracterizam a avaliação preventiva durante o monitoramento (RIBEIROFURTINI; ABREU, 2006). 
FRUET, A.P.B. et al. Legislação e implementação dos programas de controle de qualidade em frigoríficos sob fiscalização federal no Brasil. PUBVET, Londrina, V. 8, N. 13, Ed. 262, Art. 1740, Julho, 2014.

\section{Monitoração}

Os métodos de monitoramento devem ser rápidos e permitir, quando possível, que os ajustes sejam feitos antes que exceda os limites críticos (FIGUEIREDO; NETO, 2001). Observação visual, temperatura, tempo, pH e nível de umidade são exemplos de medidas para monitoração (MIYAGUSKU et al., 2011).

Ações corretivas

São ações tomadas quando os resultados da monitoração não estão satisfatórios, e indicam que o limite crítico não está sendo atendido, havendo necessidade de implementação de medidas imediatas (CONTRERAS et al., 2002). Assim, essas ações corretivas devem garantir a identificação e eliminação do desvio do limite crítico, a eficácia da ação corretiva aplicada, a adoção de medidas preventivas para evitar a recorrência se houver casos de desvios repetitivos ou graves (BRASIL, 2003). Por fim, ações corretivas e preventivas devem ser eficazes o suficiente para evitar comercialização de produtos nocivos à saúde.

\section{Procedimentos de verificação}

A aplicação de métodos de verificação, auditoria, procedimentos, testes, incluindo amostragem e análises aleatórias, podem ser utilizadas para testar se o sistema APPCC está funcionando corretamente (FIGUEIREDO; NETO, 2001).

Pode-se, ainda, distribuir os procedimentos de verificação em quatro pontos: revisão dos limites críticos para avaliar a adequação do controle dos perigos; revisão frequente do plano APPCC, inclusive dos registros, para identificar se está sendo seguido adequadamente o programa; verificação periódica dos PCC; e o processo de verificação do Serviço de Inspeção Federal (SIF) (MIYAGUSKU et al., 2011). 
FRUET, A.P.B. et al. Legislação e implementação dos programas de controle de qualidade em frigoríficos sob fiscalização federal no Brasil. PUBVET, Londrina, V. 8, N. 13, Ed. 262, Art. 1740, Julho, 2014.

\section{Registros de resultados}

Devem ser registrados no plano APPCC a relação de integrantes da equipe que realiza o plano, a descrição do produto a ser produzido, fluxograma de produção, perigos e riscos durante a produção, pontos críticos de controle, limites críticos de cada PCC, forma de monitoração, ações corretivas e preventivas, além dos registros e procedimentos para verificações (SANTOS, 2008).

A implementação do APPCC e demais programas de controle de qualidade satisfazem à legislação nacional e internacional, de forma que contribui para saúde pública e para o comércio de produtos entre países (RIBEIRO-FURTINI; ABREU, 2006).

Empresas produtoras de alimentos que seguem a legislação federal e realizam implementação adequada de programas de autocontrole contribuem para a produção de alimentos seguros, pois estes são preparados, manipulados, embalados e transportados sob condições sanitárias adequadas (SANTOS, 2008; LUNDGREN, et al. 2009). Portanto, a forma mais efetiva de garantir a produção de produtos cárneos de acordo com padrões de qualidade e inocuidade é através do monitoramento constante nas etapas do processo de fabricação (OLIVEIRA, 2011).

Estudos realizados por Gandra (2011) demonstram que há uma alta correlação entre tipos de fiscalização de frigoríficos e concentração bacteriana em carcaças. Foi observado que frigorífico sob fiscalização estadual apresenta maiores níveis de microrganismos mesófilos aeróbios e Enterobactericeae se comparado com frigorífico sob SIF, demonstrando a eficácia de programas de autocontrole exigidos. Pode-se inferir que os frigoríficos brasileiros estão em processo de evolução na implementação de programas de autocontrole com finalidade de produzir alimentos de qualidade sanitária. Essa atitude é importante para o país permanecer como maior exportador mundial de carne de frango e bovina já que, segundo França Filho et al. (2006), os mercados 
FRUET, A.P.B. et al. Legislação e implementação dos programas de controle de qualidade em frigoríficos sob fiscalização federal no Brasil. PUBVET, Londrina, V. 8, N. 13, Ed. 262, Art. 1740, Julho, 2014.

importadores são exigentes e apresentam muitos padrões peculiares para avaliar a qualidade do produto cárneo.

\section{CONCLUSÕES}

Ocorreram mudanças expressivas na legislação brasileira quanto ao controle de qualidade na produção de alimentos, as quais podem ser evidenciadas na Circular n. 175 de 2005, que uniu os principais programas em um único documento e criou assim os programas de autocontrole. Embora, a responsabilidade de produzir alimentos seguros tenha passado para as indústrias, é evidente a existência de um padrão a ser seguido pelas empresas ao aderir aos programas de controle de qualidade, de forma que a implantação adequada contribui para a produção de alimentos seguros e viabilizam a comercialização com outros países.

\section{REFERÊNCIAS}

BRASIL. Ministério da Saúde. Portaria n. 1.428 de 26 de novembro de 1993. Regulamento Técnico para Inspeção Sanitária de Alimentos. Diário Oficial da União, Brasília, 1993.

BRASIL. Ministério da Agricultura, Pecuária e Abastecimento. Portaria n. 368 de 04 de setembro de 1997. Regulamento Técnico sobre as condições Higiênico-Sanitárias e de Boas Práticas de Fabricação para Estabelecimentos Elaboradores / Industrializadores de Alimentos. Diário Oficial da União, Brasília, 1997a.

BRASIL. Ministério da Agricultura, Pecuária e Abastecimento. Circular no 272 de 22 de dezembro de 1997. Programa de Procedimentos Padrão de Higiene Operacional (PPHO) e o Sistema de Análise de Risco e Controle de Pontos Críticos (ARCPC) em estabelecimentos envolvidos com o comércio internacional de carnes e produtos cárneos, leite e produtos lácteos e mel e produtos apícolas. Diário Oficial da União, Brasília, 1997b.

BRASIL. Ministério da Agricultura, Pecuária e Abastecimento. Portaria n. 46 de 10 de fevereiro de 1998. Sistema de Análise de Perigos e Pontos Críticos de Controle - APPCC a ser implantado nas indústrias de produtos de origem animal sob o regime do Serviço de Inspeção FederalSIF. Diário Oficial da União, Brasília, 1998.

BRASIL. Ministério da Saúde. Resolução-RDC n. 275 de 21 de outubro de 2002. Dispõe sobre o Regulamento Técnico de Procedimentos Operacionais Padronizados aplicados aos

Estabelecimentos Produtores/Industrializadores de Alimentos e a Lista de Verificação das Boas Práticas e Fabricação em Estabelecimentos Produtores/Industrializadores de Alimentos. Diário Oficial de União, Brasília, 2002. 
BRASIL. Ministério da Agricultura, Pecuária e Abastecimento. Circular n. 369 de 02 de junho de 2003. Dispõe sobre instruções para elaboração e implantação dos sistemas PPHO e APPCC nos estabelecimentos habilitados à exportação de carnes. Diário Oficial da União, Brasília, 2003.

BRASIL. Ministério da Saúde. Resolução RDC n 216, de 15 de setembro de 2004. Regulamento Técnico sobre Boas Práticas para Serviços de Alimentação. Diário Oficial da União, Brasília, 2004.

BRASIL. Ministério da Agricultura, Pecuária e Abastecimento. Circular n. 175 de 16 de maio de 2005. Procedimentos de Verificação dos Programas de Autocontrole. Diário Oficial da União, Brasília, 2005a.

BRASIL. Ministério da Agricultura, Pecuária e Abastecimento. Circular n. 176 de 16 de maio de 2005. Dispõe sobre modificação das instruções para a verificação do PPHO, encaminhados pela Circular No 201/97 DCI/DIPOA e aplicação dos procedimentos de verificação dos Elementos de Inspeção previstos na Circular No 175/2005 CGPE/DIPOA. Diário Oficial da União, Brasília, 2005b.

CONTRERAS, C. C. et al. Higiene e Sanitização na Indústria de Carnes e Derivados. São Paulo: Livraria Varela, 2002, 181p.

FAO. Food and Agriculture Organization of the United Nations. Food and agricultural commodities production in 2011. 2012. Disponível em:

<http://faostat.fao.org/site/339/default.aspx>. Acesso em: 04 abr. 2013.

FIELDING, L. et al. An evaluation of process specific information resources, aimed at hazard analysis, in small and medium enterprises in food manufacturing. Food Control, v. 22, p. 1171-1177, 2011.

FIGUEIREDO, V. F. de.; NETO, P. L. de O. C. Implantação do HACCP na indústria de alimentos. Gestão \& Produção, v. 8, n. 1, p. 100-111, 2001.

FRANÇA FILHO, A. T. et al. Qualidade bacteriológica de meias-carcaças bovinas oriundas de matadouros-frigoríficos do Estado de Goiás habilitados para exportação. Ciência Animal Brasileira, v. 7, n. 3, p. 315-325, 2006.

GANDRA, T. K. V. Identificação de pontos de contaminação por Salmonella spp. e por indicadores de qualidade higiênico-sanitária no abate e processamento de bovinos. Pelotas: UFpel, 2011. Dissertação (Mestrado em Ciência e tecnologia Agroindustrial), Universidade Federal de Pelotas, 2011.

JIANU, C.; CHIS, C. Study on the hygiene knowledge of food handlers working in small and medium-sized companies in western Romania. Food Control, v. 26, p. 151-156, 2012.

KARAMAN, A. D. et al. Barriers and benefits of the implementation of food safety management systems among the Turkish dairy industry: A case study. Food Control, v. 25, p. 732-739, 2012.

KARIPIDIS, P. et al. Factors affecting the adoption of quality assurance systems in small food enterprises. Food Control, v. 20, p. 93-98, 2009.

KRYSTALLIS, A.; ARVANITOYANNIS, I. S. Investigating the concept of meat quality from the consumers perspective: The case of Greece. Meat Science, v. 72, p. 164-176, 2006.

LUNDGREN, P. U. et al. Profile of the hygienic-sanitary quality of bovine meat marketed at free markets and public markets of João Pessoa/PB-Brasil. Alimentos e Nutrição, v.20, n. 1, p. 113-119, 2009. 
ESCOLA SUPERIOR AGRÁRIA DE COIMBRA - ESAC. Manual de higienização na indústria alimentar. 2000, 40p. Disponível em:

<http://www.esac.pt/noronha/manuais/Manual_higienizao_aesbuc.pdf>. Acesso em: 04 abr. 2013.

MIYAGUSKU, L. et al. HACCP: Introdução à análise de perigos na indústria de carnes. Campinas: ITAL, Centro de Tecnologia de Carnes, 2011, 137p.

MOMBACH, J. et al. Proposta de um modelo de gestão pela qualidade para um abatedouro/frigorífico de suínos. Revista Agrarian, v. 3, n. 10, p. 293-300, 2010.

OLIVEIRA, M. G. de. Ocorrência de Listeria spp., Escherichia coli 0157:H7 e microrganismos indicadores de higiene durante as etapas de abate de bovinos e no ambiente de processamento de cortes. Pelotas: UFpel, 2011. Dissertação (Mestrado em Ciência e tecnologia Agroindustrial), Universidade Federal de Pelotas, 2011.

PRATA, L. F.; FUKUDA, T. Fundamentos de higiene e inspeção de carnes. Jaboticabal: Funep, 2001, 326p.

RIBEIRO-FURTINI, L. L.; ABREU, L. R. de. Utilização de APPCC na indústria de alimentos. Ciência agrotecnologia, v. 30, n. 2, p. 358-363, 2006.

SANTOS, R. C. dos. Manual para aplicação das Boas Práticas agropecuárias e de fabricação na agroindústria. Porto Alegre: EMATER/RS, 2008, 183p.

SEPÚLVEDA, et al. Aspects of quality related to the consumption and production of lamb meat: consumers versus producers. Meat Science,v. 87, n. 4, p. 366-372, 2011.

STANLEY, R. et al. Experiences and challenges in the development of an organic HACCP system. NJAS - Wageningen Journal of Life Sciences, v. 58, p. 117-121, 2011. 